\title{
Correction to: The 1000 Most Cited Papers on Visible Nonverbal Behavior: A Bibliometric Analysis
}

\author{
Pierrich Plusquellec ${ }^{1,2,3}$ (D) . Vincent Denault ${ }^{1,4}$
}

Published online: 22 November 2018

(c) Springer Science+Business Media, LLC, part of Springer Nature 2018

\section{Correction to: J Nonverbal Behav (2018) 42:347-377 https://doi.org/10.1007/s10919-018-0280-9}

Unfortunately, the original version of the article contained incorrect DOI listed in the abstract section. The correct DOI and link is: Whalen et al. in Emotion 1(1):70-83, 2001 https://doi.org/10.1037/1528-3542.1.1.70.

The original article can be found online at https://doi.org/10.1007/s10919-018-0280-9.

\section{Pierrich Plusquellec}

pierrich.plusquellec@umontreal.ca

1 Centre for Studies in Nonverbal Communication Sciences, Montreal, Canada

2 Research Centre, Montreal Mental Health University Institute, CIUSSS Est, Montreal, Canada

3 School of Psychoeducation, University of Montreal, PO Box 6128, Centre-ville STN, Montreal, QC H3C 3J7, Canada

4 Department of Communication, University of Montreal, Montreal, Canada 